\title{
EXPERIMENTAL ANALYSIS OF SPACE TRUSSES WITH TYPICAL CONNECTIONS REINFORCED WITH STEEL AND SISAL-RESIN SPACERS
}

\author{
Cleirton A. S. Freitas ${ }^{1, *}$, Welington V. Silva², Luciano M. Bezerra², Francisco F. S. M. Júnior ${ }^{1}$, \\ Vinícius C. P. Neto ${ }^{1}$, and Brenda A. T. Ribeiro ${ }^{1}$ \\ ${ }^{1}$ Research Group on Structural Engineering in Cariri - GPEEC, Federal University of Cariri - http://www.ufca.edu.br, Juazeiro do Norte, Brazil \\ ${ }^{2}$ Department of Civil and Environmental Engineering, University of Brasilia - UnB http://www.unb.br, Brasília, Brazil \\ *(Corresponding author: E-mail: andre.freitas@ufca.edu.br)
}

\section{A B S T R A C T}

Space trusses are reticulate systems used worldwide because of their advantages in covering roofs with large free spaces. In addition to having a low cost, the self-weight of such trusses is relatively reduced. The limitations on the use of these structures are mainly related to the fragility of the nodes, specifically those classified as typical nodes which may collaps e when submitted to service loads due to eccentricities generated by stamped connections. This fact restricts significantly the use of space trusses. Considering this fact, the present research evaluates a reinforcement proposal for the typical connections with a series of eighteen prototypes. The reinforcements tested are made with steel plates and spacers. In this work, spacers are made of steel or sisal with fiber polymer resin. Such spacers are employed to correct part of the eccentricities present at typical nodes. The experimental tests show an increase of about $40 \%$ of the resistant capacity of the truss with the proposed reinforcement avoiding the early collapse of typical nodes. In truss prototypes with typical nodes, local abrupt collapses always happened at nodes. In reinforced trusses, collapse took place by buckling of the bars at the top chord of the prototypes, therefore, taking account of the bar full resistance.
A R T I C L E H I S T O R Y

$\begin{array}{ll}\text { Received: } & \text { 26 May } 2019 \\ \text { Revised: } & \text { 17 August } 2019 \\ \text { Accepted: } & \text { 01 September 2019 }\end{array}$

\section{K E Y W O R D S}

Space trusses;

Fragility;

Experimental study;

Simple connections;

Spacers reinforcement

Copyright $@ 2019$ by The Hong Kong Institute of Steel Construction. All rights reserved.

\section{Introduction}

Space trusses are reticulate lightweight structures in 3D geometric pattern made of bars or tubes interlocked at nodes. They are frequently made of steel tubes and used in the construction of roofs over large areas with few interior supports. The reticulate tubes have several interconnections at nodes of the intersections of the tubes, like top and bottom chords, and diagonals. Space trusses are generally made with an assemblage of tetrahedral modules. There is a variety of node connections, some patented, some of the public domain. The simple and most used connection on 3D trusses is named "typical node" where flattened-end tubes are put together with a single trespassing bolt [1]

The design of space trusses is, generally, based on a nodal system that transmits only tensile and compression axial forces. The ideal node connection is not conceived to transmit a bending moment [2], but just axial forces. Therefore, in a real situation, the connection between bars or tubes must always be designed to minimize bending stresses. However, this situation is usually not possible for some connection, especially the typical connection with tubes with flattened ends (Fig. 1). Other examples of connection nodes are pointed out in Souza's research [3] (Figs. 2 and 3).

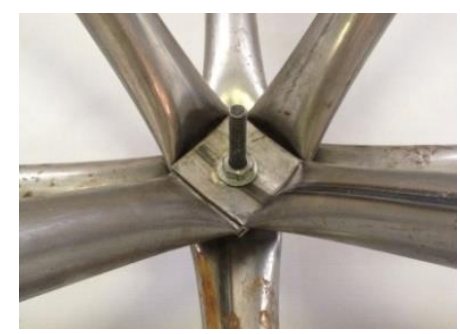

Fig. 1 Typical node

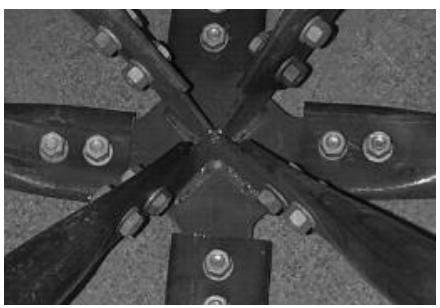

Fig. 2 Steel node [3]

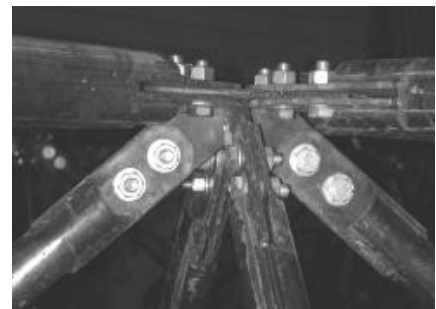

Fig. 3 Steel node made with plates [3]

Several patented systems of nodes may be found worldwide [4,5,6], (Figs. 4,5 and 6). Some node solutions can make the construction work expensive and the execution of the space truss impractical. Usually, the simplest and economical option is the use of the typical nodes. In such a connection the ends of the tubes are stamped, flattened, and put together with a single trespassing bolt (Fig. 1). This system is widely used due to its facilities in the manufacture, transportation, assemblage, and low cost [8].

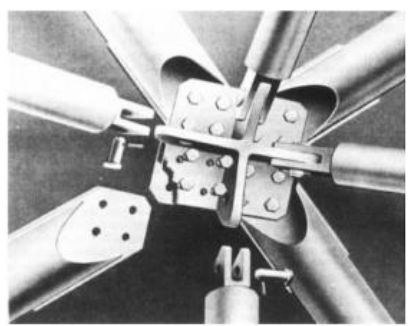

Fig. 4 Rai joint - Holland $[5]$

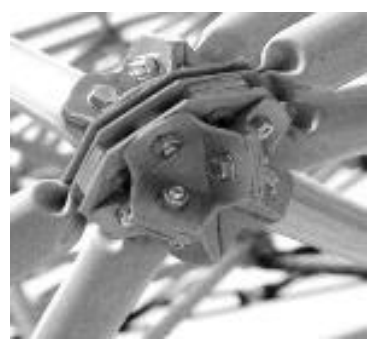

Fig. 5 Eco - Italy[5] 


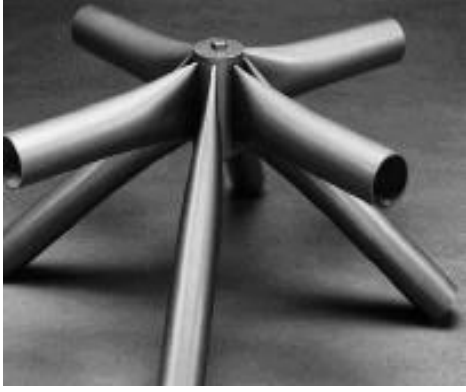

Fig. 6 Triodetic - Canada [5]

This research motivation is related to the fact that the space trusses frequently present local instabilities [8], especially, at the link between the tube ends (Fig. 1). Such nodes present fragility when under stress, showing highly distortions and local collapse before the buckling of the tubes - as can be observed in (Fig. 7) [9]. This problem is explained by the geometric changes generated at the tube ends [10], due to the smashing of the bar ends. This produces eccentricities in the connections [7] reducing the load capacity of the structure [11]. Some collapses of the connections have been reported, such as the ones in Spain [11] and Brazil [12] (Fig. 8) [9]. Other examples of 3D truss collapse in the world, like the dome in Romania, Burcharest, 1963, in Hartford USA, 1978, in Malaysia, 2009, are reported in [13].

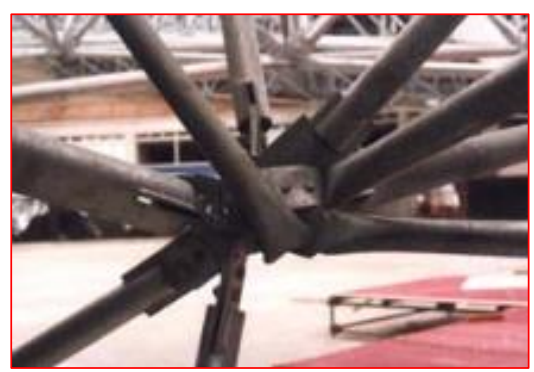

Fig. 7 Node failure [9]
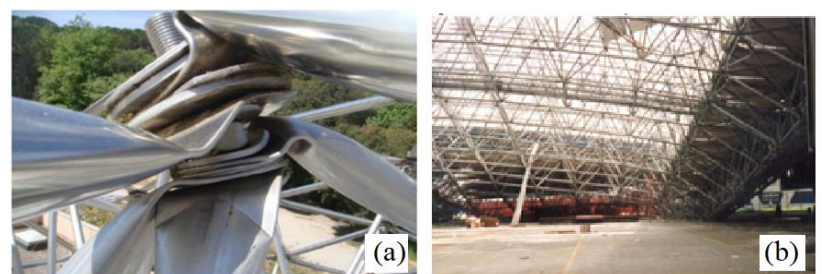

Fig. 8 Collapse of space trusses: (a) In Spain [11], (b) In Manaus [12]

Typical nodes, like the one in Fig. 1, show eccentricities $E_{1}$ and $E_{2}$ that can be seen in Fig. 9 and such eccentricities contribute to local collapse. The proposal for the solution of early local collapse at the nodes of 3D trusses with typical nodes was to improve the efficiency of such connections. The correction consists of removing, at least one of the eccentricities, $\mathrm{E}_{2}$, due to the flattened ends of the tubes connected at the node - as shown in Fig. 09 [11]. Such correction can be done with low-cost spacers easy to be applied (Fig. 10). Lab tests show eccentricity E1 does not play an important role [11, 14].

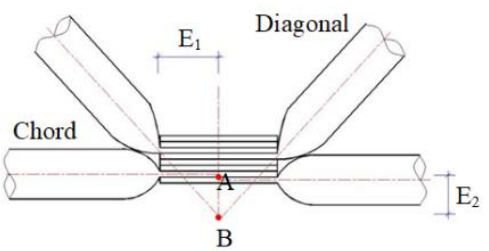

Fig. 7 Eccentricities [14]
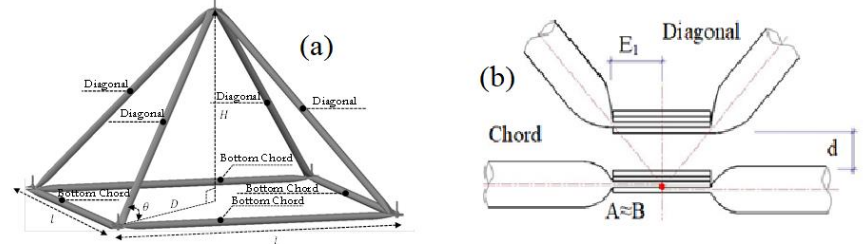

Fig. 8 Correcting eccentricity [14]

Space trusses are made of connections between tetrahedron or pyramids, as shown in Figs. 8b and 10a. The use of spacers aims to reallocate the diagonal bars (as in Fig. 10b) and, consequently, eliminate eccentricity $E_{2}$. With a spacer with height $d$ (Fig. 10b), the moments at the typical node can be substantially reduced. This is because normal forces generated by the diagonals can now converge to the central axis of the chords. The distance $d$ is given as a function of the length of the chord $l$, the height $H$ and the tube thickness $t$ [11] (see Fig. $10 \mathrm{a})$. Given $E_{l}, d$ can be calculated according to Equation 1:

$d=\frac{2 H E_{1}}{l \sqrt{2}-4 E_{1}}-8 t$

\subsection{Preliminary steps in this research}

Recent studies carried out in the Structural Laboratory of the Research Group on Civil Engineering Structures (GPEEC) at the Federal University of Cariri (UFCA) in prototypes $[11,14,15]$ evaluated the performance of $3 \mathrm{D}$ trusses with spacers correcting the typical nodes. Initially, twelve truss specimens were tested in the Structural Lab of the University of Brasilia (UnB). They were divided into groups of three prototypes with the following differences: (1) Typical Connection (LTE), (2) Typical Connection with Steel Spacer (LTDE), and (3) Typical Connection with Steel Spacer and Steel Plate

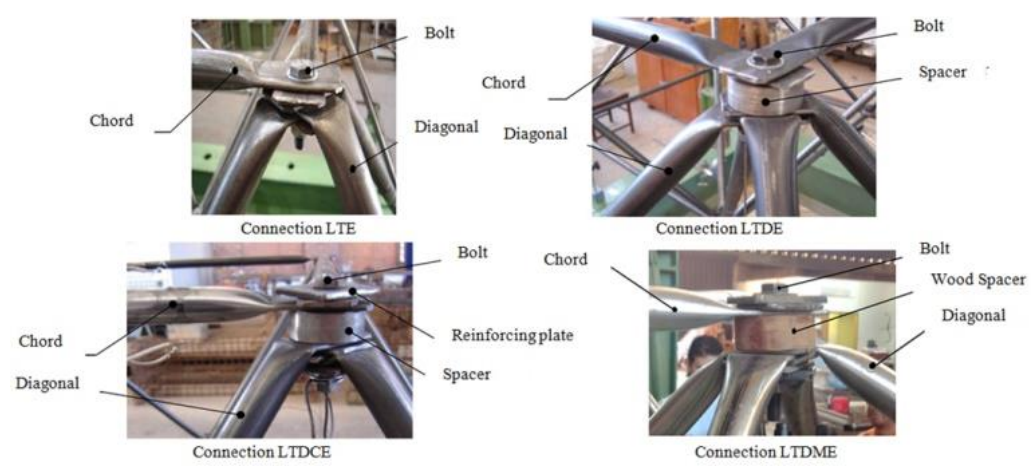

(LTDCE), and (4) Typical Connection with Wood Spacer (LTDME), as shown in Fig. 11 [14].

Fig. 9 Types of prototypes tested in the structural laboratories of UnB and UFCA

The geometry of the pyramid module (Fig. 10a and 12) has the base and height, respectively, equal to $1000 \mathrm{~mm}$ and $707 \mathrm{~mm}$. With the use of steel spacers, tests in

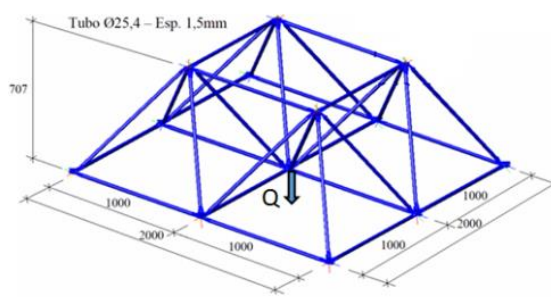

Space Truss LTE (mm) the the prototypes indicated a resistance improvement of approximately $40 \%$ of the load capacity in comparison with typical node connections, according to the prototypes in Fig. 13. 


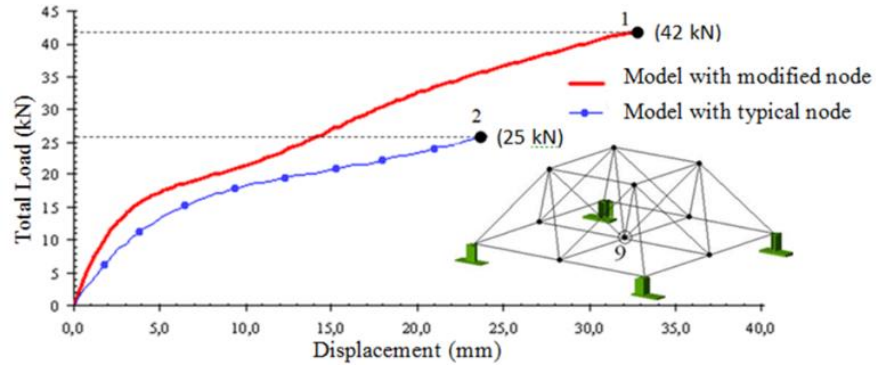

Fig. 10 Geometry of the prototype [15].

The results in Fig. 13 show that the LTE prototype presented local collapse at the node with an average of collapse load of $25 \mathrm{kN}$ and after reaching that value, the truss collapsed globally. The use of typical nodes should be avoided because the collapse of the node was abrupt. In this case, the maximum capacity of the bars was not reached. Moreover, there was a $32.75 \%$ increase in deflection compared to the prototypes with spacers. On the other hand, the LTDE prototypes had a $35.9 \%$ increase in the resistance capacity compared to LTE connection, with a $35.87 \mathrm{~mm}$ overall displacement.

Fig. 11 Average Load vs Displacements for prototypes with typical node and prototypes with spacers (modified node) [1]

It is observed (Fig.14) an increase in stiffness due to eccentricity correction since the mechanism of the collapse was by buckling of the bar. The LTDCE (Fig.16) prototypes truss presented the best behavior. In this case, the resistance gain was $40.77 \%$ compared to the LTE prototypes (Fig.15). The $31.75 \mathrm{~mm}$ displacement proved the efficiency of the reinforcement plate on the connection,

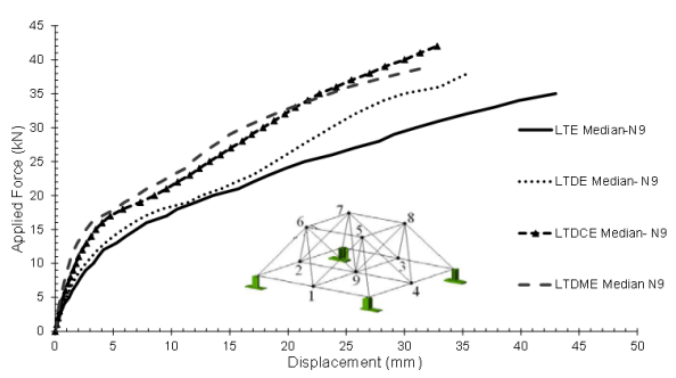

increasing the node stiffness (Fig. 17). Finally, the LTDME (Fig. 18) prototypes also showed better resistance than the LTE prototypes arriving to a collapse load of $39.68 \mathrm{kN}$. Table 1 reports a summary of the tests.

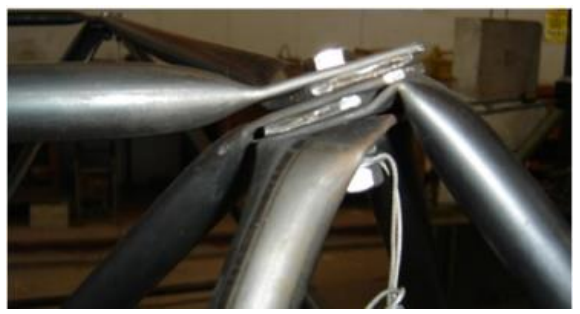

Fig. 12 Average curves for Loads vs displacements for prototypes tested in [1]

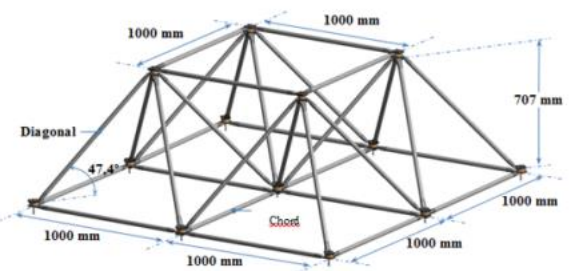

Space Truss LTDE, LTDCE and LTDME

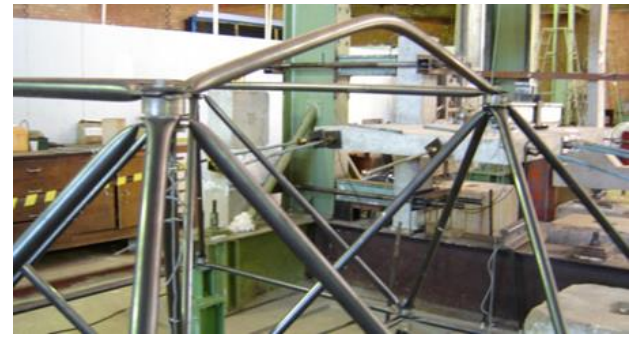

Fig. 14 Collapse for prototypes with LTDCE $(42 \mathrm{kN})$ [1].

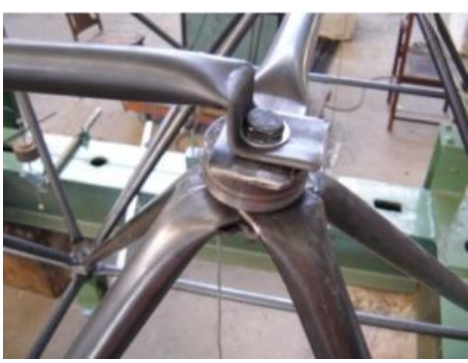

Fig. 15 Collapse of LTDE (38kN) [14]

Table 1

Summary of the LT, LTD, LTDC, and LTME test results

\begin{tabular}{|c|c|c|c|c|c|c|c|}
\hline \multirow{2}{*}{ Prototypes } & \multirow{2}{*}{$\begin{array}{r}\text { Model of } \\
\text { Connection }\end{array}$} & \multirow{2}{*}{$\begin{array}{c}\text { Dimensions } \\
(\mathrm{mm})\end{array}$} & \multicolumn{2}{|c|}{ Element } & \multirow{2}{*}{\multicolumn{2}{|c|}{$\begin{array}{c}\text { Ultimate } \\
\text { oacer Load }(\mathrm{kN})\end{array}$}} & \multirow{2}{*}{$\begin{array}{l}\text { Collapse } \\
\text { Mode } \\
\end{array}$} \\
\hline & & & Chord & Diagonal & & & \\
\hline PROT 1 & LT 1 & & $16 \varphi 25 \times 1060$ & $16 \varphi 25 \times 1076$ & --.- & 25,33 & Node collapse \\
\hline PROT 2 & LT 2 & $2000 \times 2000$ & $16 \varphi 25 \times 1060$ & $16 \varphi 25 \times 1076$ & -..- & 25,89 & Node collapse \\
\hline PROT 3 & LT 3 & & $16 \varphi 25 \times 1060$ & $16 \varphi 25 \times 1076$ & -..- & 25,78 & Node collapse \\
\hline PROT 1 & LTD 1 & & $16 \varphi 25 \times 1060$ & $16 \varphi 25 \times 1076$ & 13 & 39,63 & Local bar collapse \\
\hline PROT 2 & LTD 2 & $2000 \times 2000$ & $16 \varphi 25 \times 1060$ & $16 \varphi 25 \times 1076$ & 13 & 40,14 & Local bar collapse \\
\hline PROT 3 & LTD 3 & & $16 \varphi 25 \times 1060$ & $16 \varphi 25 \times 1076$ & 13 & 36,91 & Local bar collapse \\
\hline PROT 1 & LTDC 1 & & $16 \varphi 25 \times 1060$ & $16 \varphi 25 \times 1076$ & 13 & 42,21 & Bar stability \\
\hline PROT 2 & LTDC 2 & $2000 \times 2000$ & $16 \varphi 25 \times 1060$ & $16 \varphi 25 \times 1076$ & 13 & 42,13 & Bar stability \\
\hline PROT 3 & LTDC 3 & & $16 \varphi 25 \times 1060$ & $16 \varphi 25 \times 1076$ & 13 & 41,74 & Bar stability \\
\hline PROT 1 & LTM 1 & & $16 \varphi 25 \times 1060$ & $16 \varphi 25 \times 1076$ & 13 & 39,10 & Bar stability \\
\hline PROT 2 & LTM 2 & $2000 \times 2000$ & $16 \varphi 25 \times 1060$ & $16 \varphi 25 \times 1076$ & 13 & 39,68 & Bar stability \\
\hline PROT 3 & LTM 3 & & $16 \varphi 25 \times 1060$ & $16 \varphi 25 \times 1076$ & 13 & 38,80 & Bar stability \\
\hline
\end{tabular}

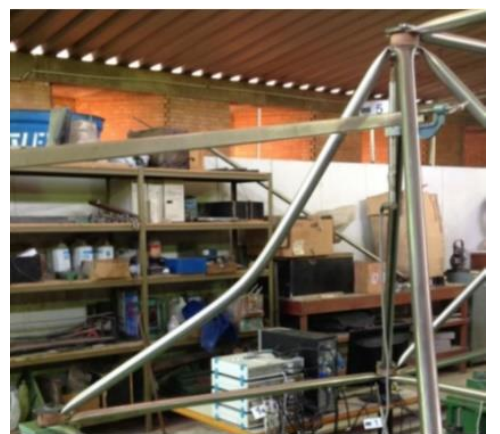

Fig. 16 Collapse of LTDME (P1 - 39kN)

In the Federal University of Cariri - UFCa, other spacers were developed for applications to space trusses [1]. To tests such spacers, new prototypes in real scale $6000 \mathrm{~mm}$ x $9000 \mathrm{~mm}$ were built up with pyramids connected through their vertices. Each pyramid had a lateral length $l=1500 \mathrm{~mm}$ of square base and height $H=1061 \mathrm{~mm}$. The inclination angles of the diagonals were $45^{\circ}$ relative to the base plane of the pyramid. The steel tubes of the space truss were $38 \mathrm{~mm}$ $\left(1 \frac{1 / 2}{2}\right.$ in) in diameter and $1.20 \mathrm{~mm}(0.047$ in) thick.

The tubes were made from the Brazilian steel MR250, with properties equivalent to the ASTM A36. In the reinforced nodes, a $4.76 \mathrm{~mm}$ thick reinforcement plate was used. Fig. 19 shows the typical node and Fig. 20 shows the node corrected with spacers and reinforced with a superposing round plate [1].

Fig. 13 Collapse for prototypes with LTE $(25 \mathrm{kN})[1]$. 


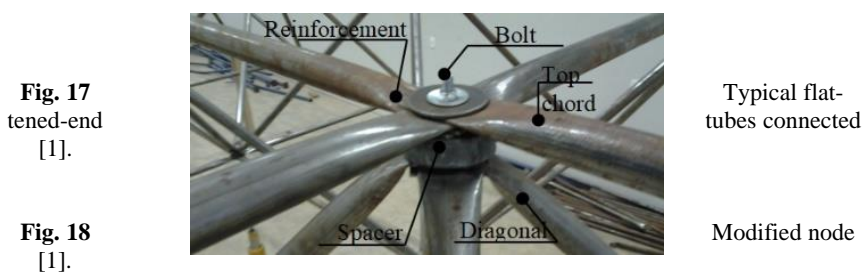

The results obtained in the lab experiments (Fig. 21) [1] showed that

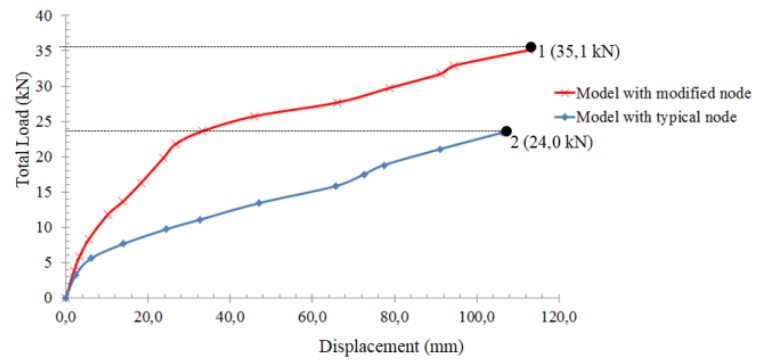

prototypes with typical connections presented excessive deformations of 106 $\mathrm{mm}$ at $24 \mathrm{kN}$ collapse load. The LT prototypes collapsed locally at the node, as can be seen in Fig. 22. The use of reinforced nodes with spacers and plate resulted in a significant decrease of the deformations compared to the typical node prototype of about $45 \mathrm{~mm}$, for the same loading conditions. A buckling collapse of the bars at the top chords in the prototype with spacers and reinforcement plates was observed - see Fig. 23.

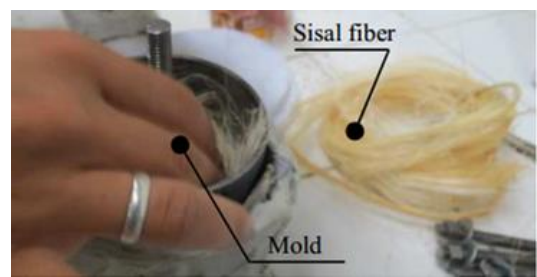

Fig. 19 Loads vs displacements for the experimental tests in [1]

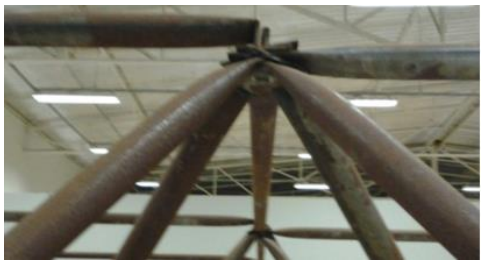

Fig. 20 Collapse in typical node $(24 \mathrm{kN})[1]$

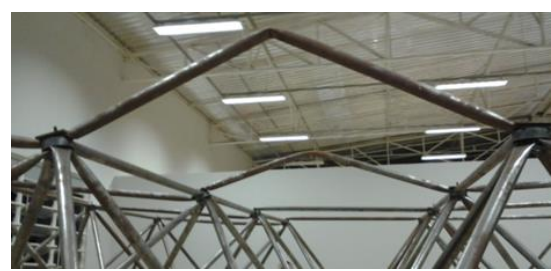

Fig. 21 Collapse in modified typical node prototype $(35.1 \mathrm{kN})[1]$

\section{New experimental studies with new spacers}

\subsection{New materials for spacers used in this research}

Although the previous studies [1] have demonstrated the efficiency of the steel spacers in the typical nodes, their use, significantly, increases the cost and the self-weight of the $3 \mathrm{D}$ truss. The present research evaluates the performance of the connections with more economical spacers, comparing them with the steel spacers. All prototypes were tested in the Structural Laboratory of the
Civil Engineering Department of the Federal University of Cariri.

Fiber-reinforced polymer (FRP) is a composite material made from a fiber-reinforced polymer, widely used in the aerospace, automotive, marine, and construction industries. The polymer is usually developed from a thermosetting epoxy, vinyl ester, polyester resin or phenol-formaldehyde resin and the fibers are generally glass, carbon, basalt, aramid, paper or wood. Based on the worldwide adoption of FRP, a new material was used in the manufacturing of spacers: sisal with resin. Sisal is a natural fiber [16] and together with the resin resulted in a material with a high modulus of elasticity and good mechanical strength [17]. Other advantages of this compound are the low cost, renewable source and easy reachability in Brazil. The northeastern region of Brazil is the world's largest sisal exporter with $52 \%$ of the whole production. Brazilian sisal exportation is largely directed to Europe, Asia, and North America $[18,19]$.

Sisal is a species native to Central America, with the botanical name of Agave Sisalana (Fig. 24). Sisal fiber has traditionally been used in the textile industry but has many other uses. Thus, this research developed a Polymer Reinforced with Sisal Fiber (PRSF) as spacers to correct the typical nodes. The following images show the sisal placed in the steel mold (Fig. 25) and soaked with epoxy resin (Fig. 26), after two hours the spacer is extracted from the mold, see Fig. 27. Finally, the details of the constituent elements of the space truss, as well as their dimensions and specifications are presented in Fig. 28.

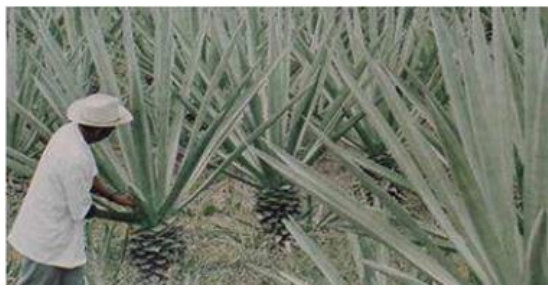

Fig. 22 Sisal farm [15]

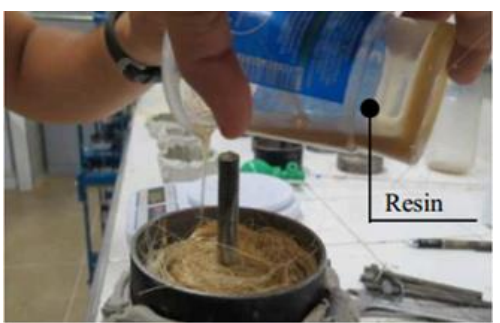

Fig. 23 Steel mold for make as space with PRSF

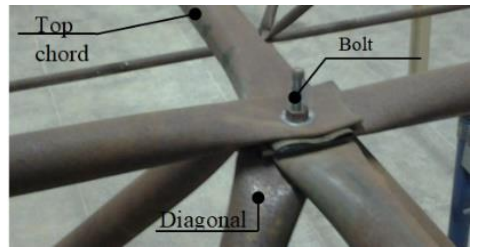

Fig. 24 Mold filled with resin and sisal fibers [15]

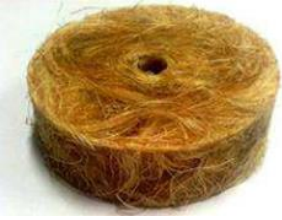

Fig. 25 Spacer made with sisal and resin PRSF [15] 


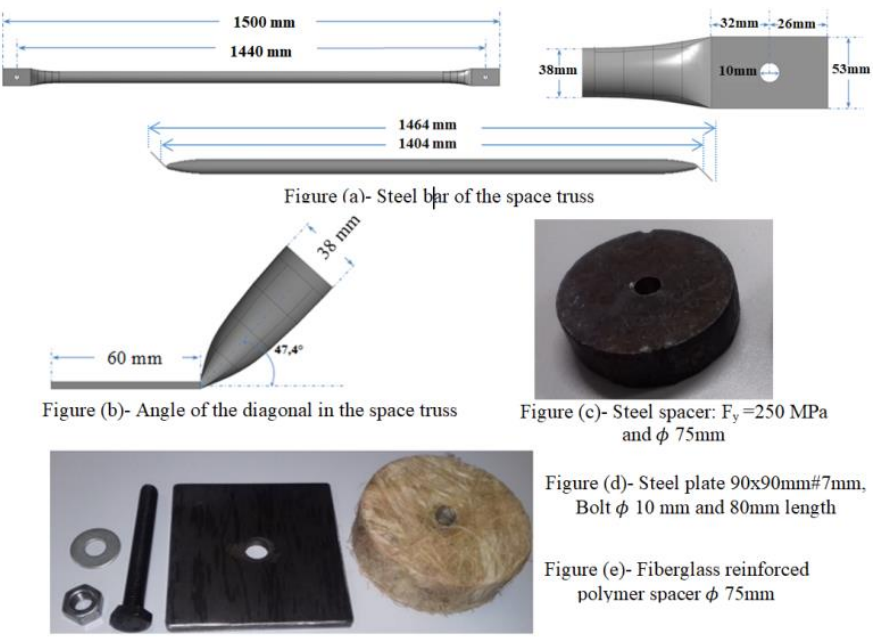

Fig. 26 Detail of the assembly of prototypes

\subsection{Methodology to assemble the space truss}

The experimental tests evaluated six prototypes, two for each type of the three connections: (1) Typical Connection without spacer (LT), (2) Typical Connection with Steel Spacer (LTDA), and (3) Typical Connection with Sisal Spacer (LTDS). The prototypes were made of 192 bars, and 56 nodes. Of all bars, 96 were diagonals, 38 top chords, and 58 bottom chords, Fig. 29. The connections were done with bolts, nuts, washers, spacers, and reinforcement plates, depending on the prototype under test - see Figs. 30, 31 and 32. The tests used new tubes for each connection type tested. Tubes were made of MR 250 steel with engineering properties similar to ASTM A36 steel (yielding stress, $\mathrm{Fy}=250 \mathrm{MPa}$ ) as the twelve initial experiments at UnB. The 3D trusses were assembled in the same way, with different spacers. Table 2 summarizes the prototypes tested and also presents the collapse load of each prototype.

\section{Table 2}

Denomination of Prototype

\begin{tabular}{|c|c|c|c|c|}
\hline Prototypes & Identification & Designation & $\begin{array}{c}\text { Total Load } \\
\mathrm{kN}\end{array}$ & Collapse \\
\hline $\begin{array}{l}\text { PROT } 1 \\
\text { PROT } 2\end{array}$ & $\begin{array}{l}\text { LT 01 } \\
\text { LT 02 }\end{array}$ & $\begin{array}{l}\text { Typical Connection LT without } \\
\text { spacer }\end{array}$ & $\begin{array}{c}30,90 \\
30,4\end{array}$ & $\begin{array}{l}\text { Node Collapse } \\
\text { Node Collapse }\end{array}$ \\
\hline $\begin{array}{l}\text { PROT } 3 \\
\text { PROT } 4\end{array}$ & $\begin{array}{l}\text { LTDA } 01 \\
\text { LTDA } 02\end{array}$ & $\begin{array}{l}\text { Typical Connection With Steel } \\
\text { Spacer }\end{array}$ & $\begin{array}{l}42,4 \\
42,5\end{array}$ & $\begin{array}{l}\text { Bar Buckling } \\
\text { Bar Buckling }\end{array}$ \\
\hline $\begin{array}{l}\text { PROT } 5 \\
\text { PROT } 6\end{array}$ & $\begin{array}{l}\text { LTDS } 01 \\
\text { LTDS } 02\end{array}$ & $\begin{array}{l}\text { Typical Connection with Sisal } \\
\text { Spacer }\end{array}$ & $\begin{array}{c}42,0 \\
44,90\end{array}$ & $\begin{array}{l}\text { Bar Buckling } \\
\text { Bar Buckling }\end{array}$ \\
\hline
\end{tabular}

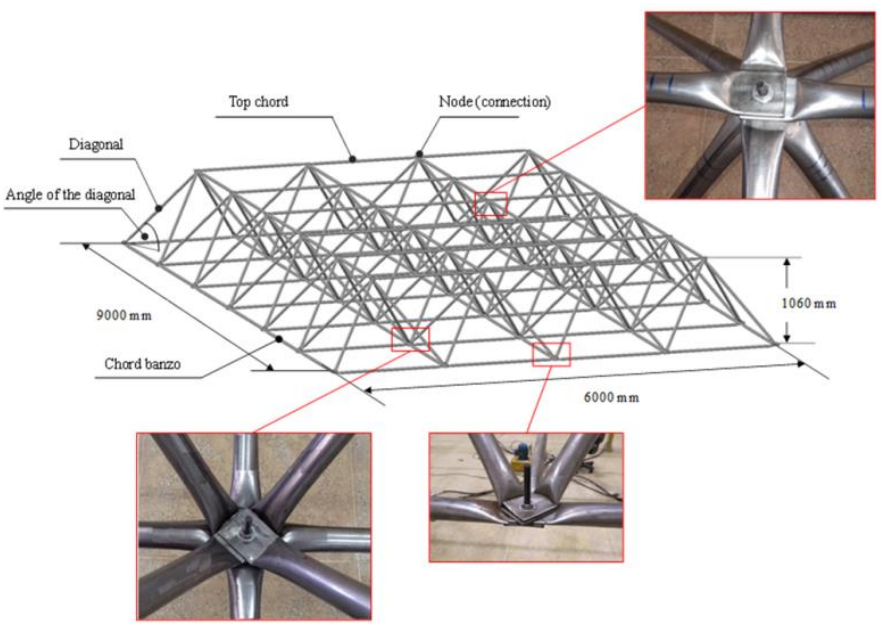

Fig. 27 Prototype of the space truss with typical connection LT

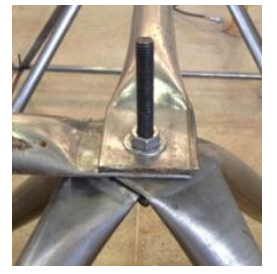

Fig. 28 Example of LT

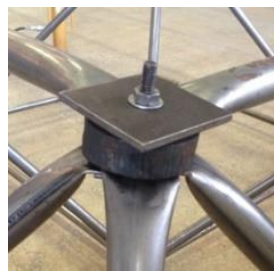

Fig. 29 Example of LTDA

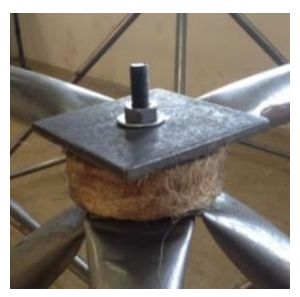

Fig. 30 Example of LTDS

\subsection{Experimental Program}

The space trusses were raised as shown in Fig. 33. The instrumentation process began with the placement of load cells, reading panels, analog deflectometers, and steel cables to apply the load to the truss through the hydraulic jacks. After the tests, the data obtained through the load control panels and deflectometers were processed. Results were arranged in graphs to show the behavior of the 3D trusses relative to each type of node tested.

All the space trusses were assembled following a sequential connection of bars keeping the symmetry of the truss. All prototypes were initially prepared on the floor of the laboratory and then lifted by a hydraulic jack up to the top of four steel columns. To standardize the tightening of all connection bolts, the tightness of the bolt was measured with a torque meter with an intensity of 50 $\mathrm{Nm}$ - this value was previously calculated [11]. The data were obtained by reading the loads on digital panels connected to load cells and analog deflectometers attached to the connections. Fig. 34 shows the application of the loads. The direction of the load application was in the direction of the gravitational force so that the structure was pulled down by the hydraulic jacks that were attached to the reaction floor of the laboratory.

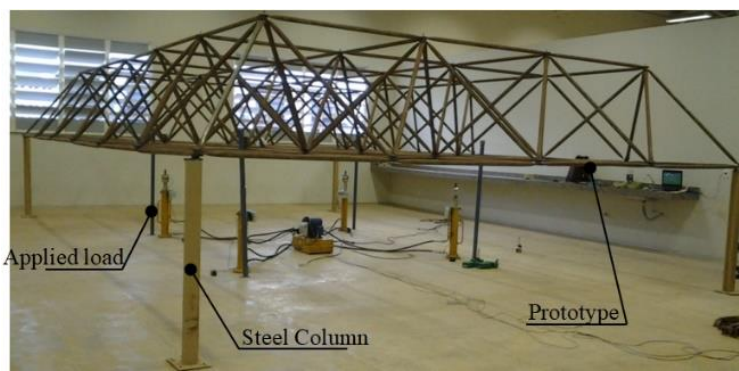

Fig. 31 Prototypes in the Laboratory at UFCa [1]

The accuracy of the deflectometer was $0.01 \mathrm{~mm}$ and the maximum reading was $30 \mathrm{~mm}$. Each load cell had a capacity of $20 \mathrm{kN}$. Load-measuring panels were installed to monitor the loads applied from the hydraulic jacks. Four nodes were used to transfer the load from the hydraulic jack to the truss prototypes. The load was applied to the four nodes over a wooden block to avoid stress concentration. The pressure of the hydraulic jacks was controlled by the pump controller as shown in Fig. 35. The readings were performed at each $0.25 \mathrm{kN}$ load step. The applied load was gradually increased until the collapse of the $3 \mathrm{D}$ 
truss. The results were arranged in spreadsheets with the reading loads and the respective displacements obtained from the deflectometers.

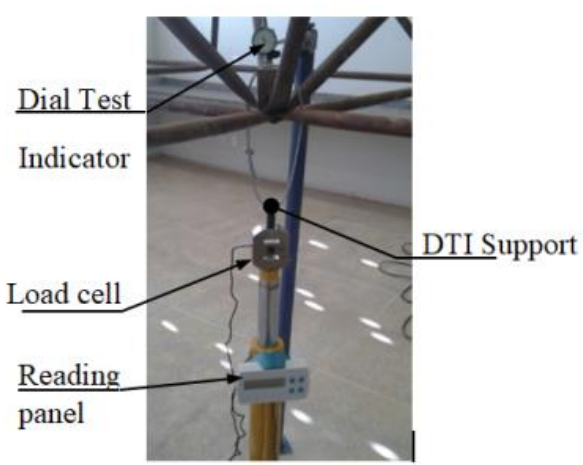

Fig. 32 Measuring system

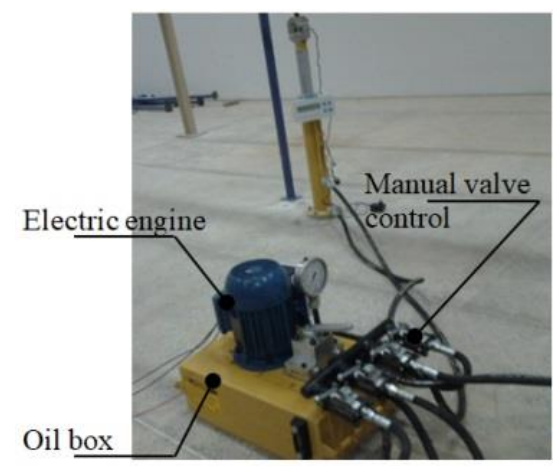

Fig. 33 Hydraulic pump control

\section{Results}

Load vs displacement data from tests are now presented. Result data shows the behavior of the different prototypes with different types of node connections. The measurements were done during the whole loading process until the overall collapse of the truss prototype is reached. The total applied load is the sum of the loads (Q1, Q2, Q3, Q4) applied individually by the four hydraulic jacks at the points as indicated in Fig. 36. The average displacement is computed from the four reading points where the loads are applied. Thus, $\mathrm{X}$-Y graphs with displacements at the $\mathrm{X}$-axis and loads at the $\mathrm{Y}$-axis express the overall behavior of the $3 \mathrm{D}$ trusses.

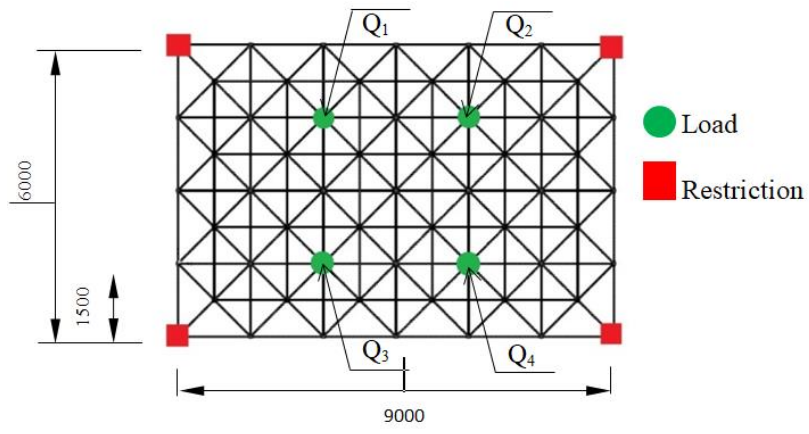

Fig. 34 Top view of the prototype (Units in Millimeter) [1]

\subsection{Results of the Typical Node without Spacer}

The two tests performed with the prototypes LT-01 and LT-02 presented similar results as expected. The LT-01 prototype test showed the collapse of the truss with an applied total load of $30.9 \mathrm{kN}$, with a mean displacement of 119.80 $\mathrm{mm}$ measured from the nodes of the applied loads - as can be seen in Fig. 37.

The values obtained in the second LT-02 test showed that its collapse occurred at $30.4 \mathrm{kN}$ load and $119.5 \mathrm{~mm}$ average deflection, see Figs. 38. This shows the quality of the truss prototypes tested in this research.

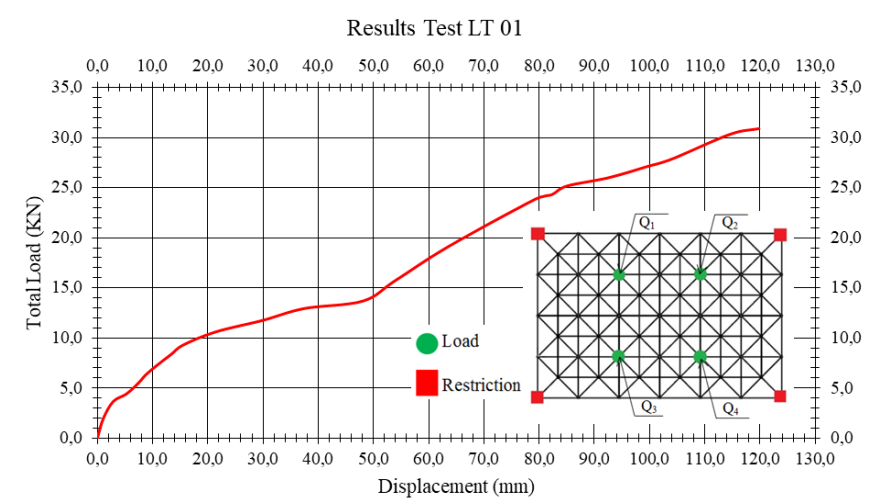

Fig. 35 Load versus Displacement for LT-01

Teste Results LT 02

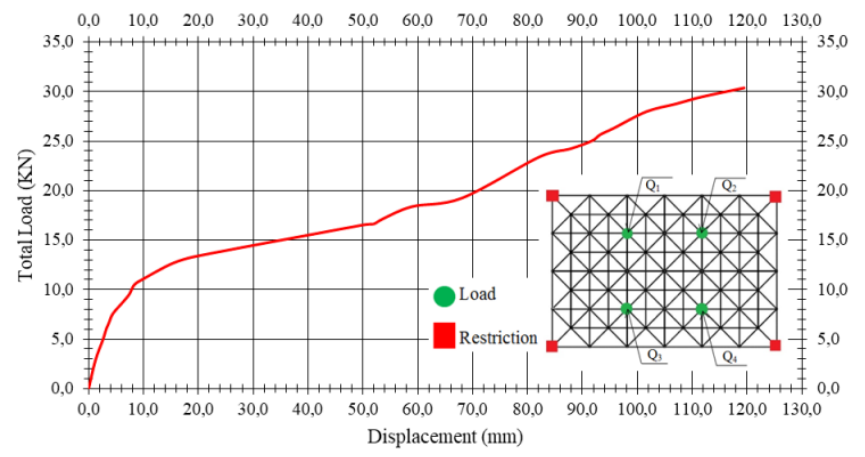

Fig. 36 Load versus displacement for LT-02

In agreement with the results obtained in previous studies [1, 2, 11, 12, 13] when typical nodes are used, collapse happened locally at nodes. The deformed connections at collapse showed significant rotations due to the presence of bending moments. They also show excessive deformation and failure of the top chords in the vicinity of the typical connection - see Figs. 39 and 40.
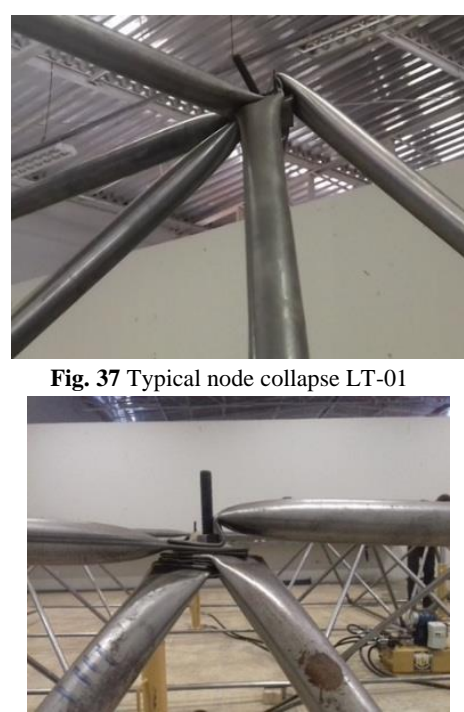

Fig. 38 Typical node collapse LT-02

\subsection{Results of the Typical Node with Steel Spacer}

The tests with these prototypes using LTDA spacers showed improvement due to the eccentricity correction of the typical node. LTDA brought a substantial decrease of the bending moments at the nodes and took advantage of the maximum strength of the steel bars. LTDA-01 prototype came to rupture at $42.4 \mathrm{kN}$ and $99.8 \mathrm{~mm}$ deflection, Fig. 41.

In the LTDA-02 prototype, the rupture was at $42.5 \mathrm{kN}$ at an average displacement of $107.2 \mathrm{~mm}$ (Fig. 42). In both prototypes collase took place at the top chord of the trusses. 


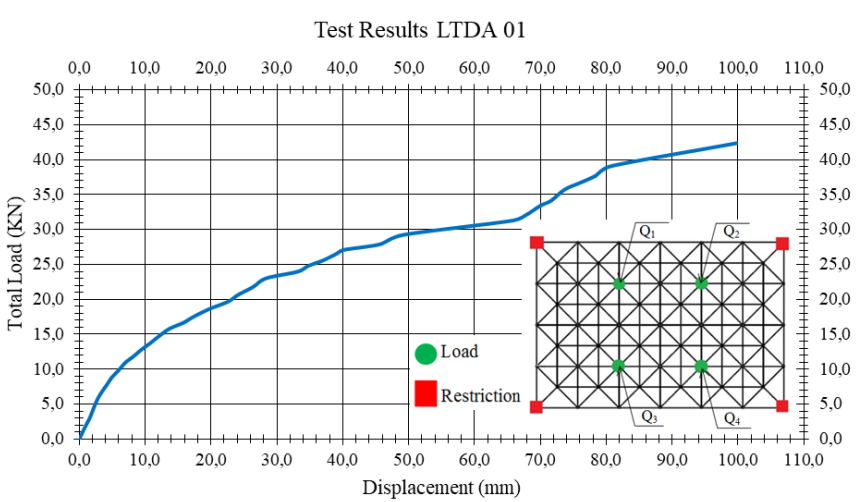

Fig. 39 Load versus displacement for LTDA-01.

Test Results LTDA 02

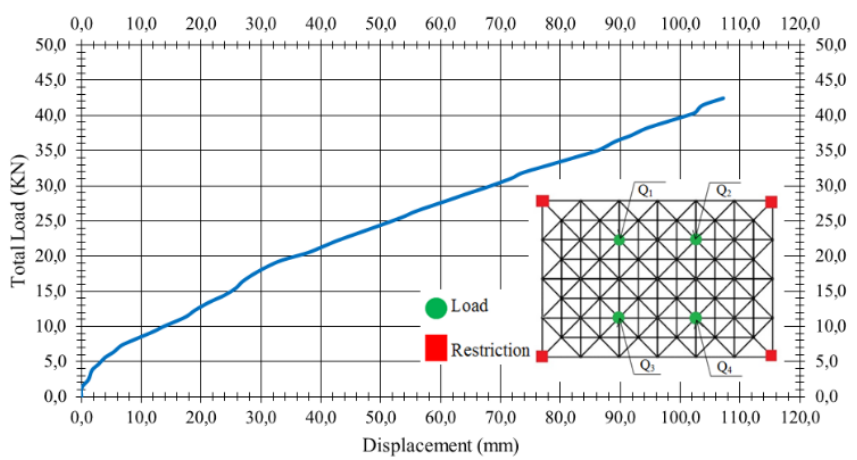

Fig. 40 Load versus displacement for LTDA-02.

The collapse of the two prototypes tested was by buckling of the top chord tubes, at the truss central span, see Fig. 43 and 44. It is observed a linear behavior of the prototype LTDA-01 until reaching the load of $19.70 \mathrm{kN}$. In prototype LTDA-02, collapse was of approximately at $20,04 \mathrm{kN}$ compared to $10,05 \mathrm{kN}$ of the LT-02 prototype. The distribution of load in the prototypes with spacers resulted in a soft break by the buckling of top chords, and no local distortion at nodes, see Fig. 45 and 46.

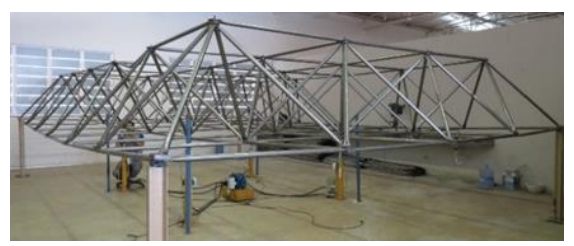

Fig. 41 Detail of deformed chord for LTDA-01

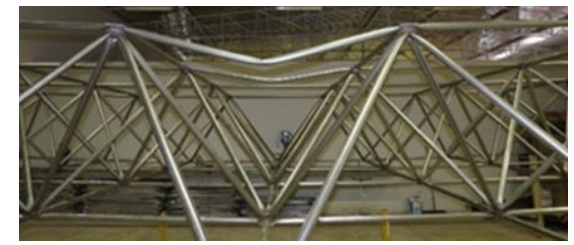

Fig. 42 Detail of buckled chord for LTDA-02

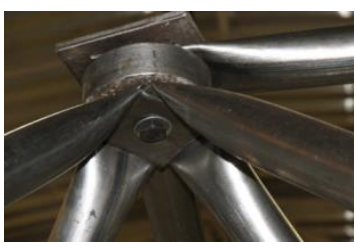

Fig. 43 No local collapse of node at chord buckling for LTDA-02

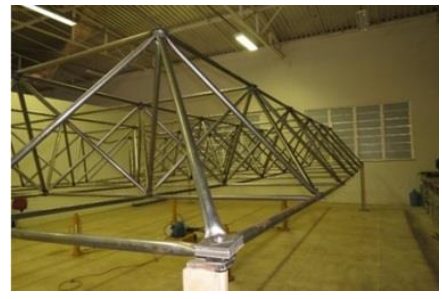

Fig. 44 Detail of nodes for LTDA-02.

\subsection{Results of the Typical Node with Sisal-Resin Spacer}

Prototype LTDS-01 showed collapse at $42 \mathrm{kN}$ and a respective average displacement of $114.5 \mathrm{~mm}$, see Fig. 47. The LTDS-02 prototype collapsed at $44.9 \mathrm{kN}$ load with an average displacement of $95.00 \mathrm{~mm}$, see Fig. 48.

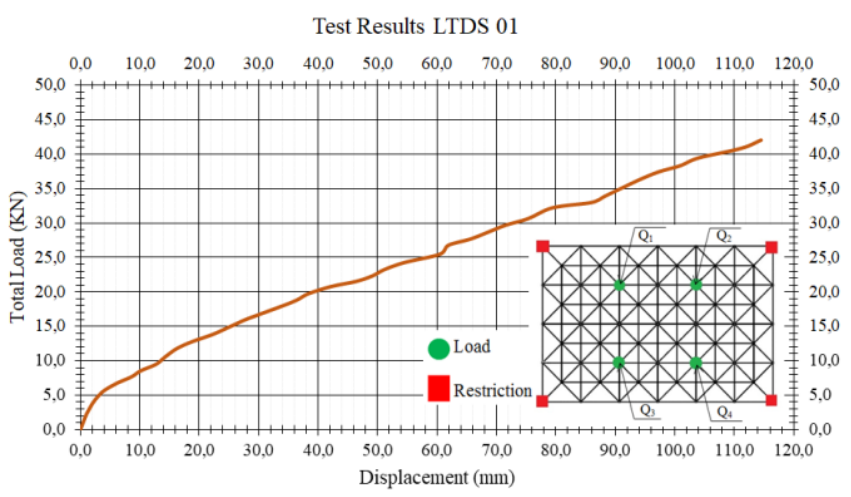

Fig. 45 Load versus Displacement for LTDS-01. Test Results LTDS 02

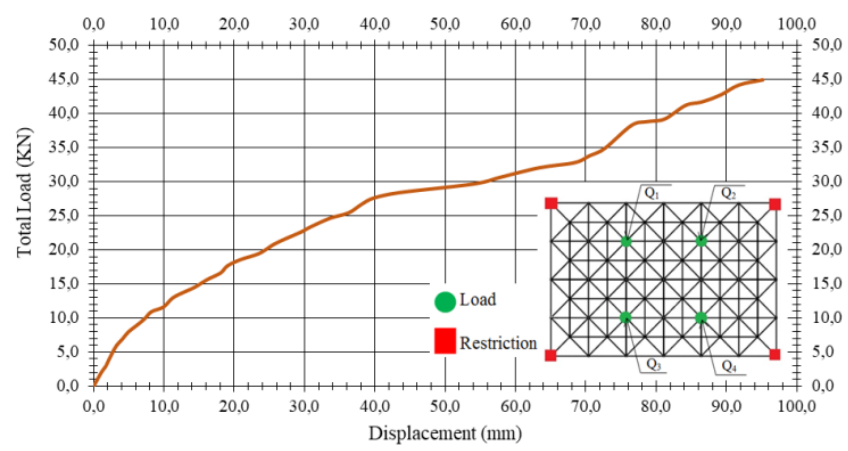

Fig. 46 Load versus Displacement for LTDS-02.

The collapse identified in LTDS prototypes was by buckling due to the compressed bars of the top chords, Fig. 49. All 56 connections were analyzed at the end of the test and no local failure of the node was observed (see Fig. 50). All spacers remained intact too, confirming the node resistance increase (Figs 51 and 52).

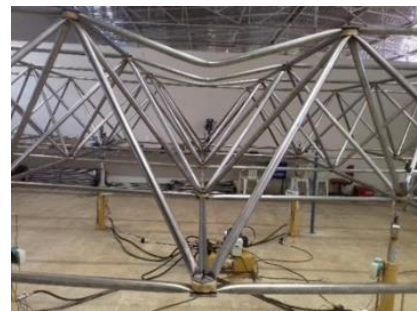

Fig. 47 Buckling of the top cords for LTDS prototypes 


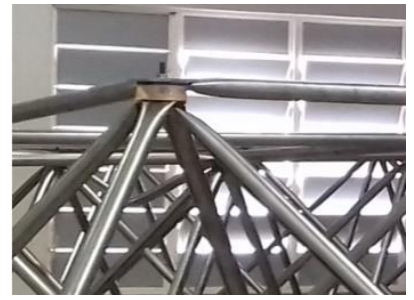

Fig. 48 Node after collapsing the Structure

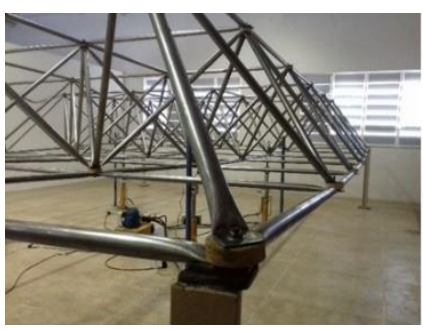

Fig. 49 Lateral deformation

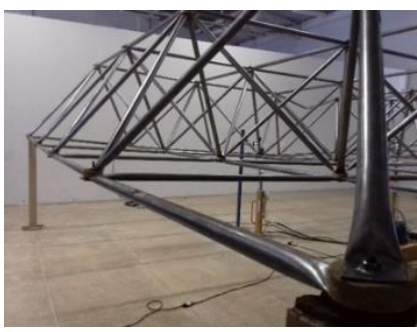

Fig. 50 Lateral Deformation

Comparasion of the Test

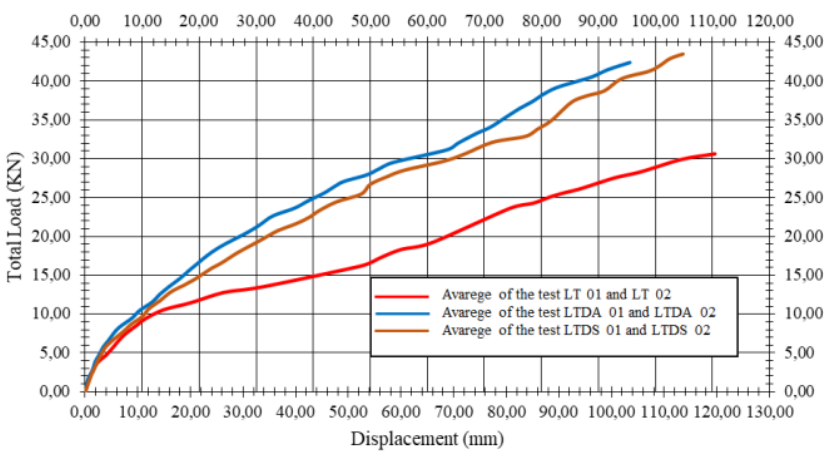

Fig. 51 Average curves comparing prototypes' performance in this research

\subsection{Comparison of all the Tests}

The graph in Fig. 53 shows the rates of the load vs displacement during the experimental tests performed with different types of connections. The proposed modifications represented substantial improvement in the strength of the trusses when steel spacers or sisal-resin spacers are used. The increase in load capacity was about $40 \%$ in the collapse loads compared to trusses with nodes without spacers, the typical nodes commonly found worldwide. The tests performed with the sisal-resin spacers showed goos performance and strength increase of the truss. Collapse loads were, on average, $6 \%$ slightly better than that obtained with the steel spacers. This minor improvement in strength may be explained due to the lower self-weight of the sisal-resin spacers compared to the overload steel spacers produce on trusses.

\section{Conclusion}

Space trusses with typical nodes made with tubes with flattened-ends trespassed by a single bolt are used worldwide. They are easy to do, but this type of connection may collapse at early load stage due to instabilities at such typical nodes. This research proposed and tested a solution to how typical nodes can gain resistance. Spacers and reinforcement plates were tested in 18 specimens of 3D trusses of two different dimensions. The test results reported in this paper showed that spacers and reinforcement plates provide a significant improvement of the typical nodes of about $40 \%$ gains in the load capacity of $3 \mathrm{D}$ truss. The results show the effectiveness of spacers in correcting eccentricity in
3D trusses made with typical nodes. Tests done in prototypes with typical nodes showed local instability of the nodes due to eccentricities. Prototypes tested using typical nodes reinforced with steel plates and spacers showed that the bad effect of eccentricities can be removed. With spacers, instead of the local collapse of the nodes, truss collapse achieved the buckling of the compressed tubes. This was observed in the tests of the prototypes with steel spacers (LTDA-01 \& LTDA-02) and with sisal-resin spacers (LTDS-01 \& LTDS-02). In both, the maximum strength of compressed tubes was reached.

The test results with sisal-resin spacers proved to be equivalent to the results obtained with steel spacers - in fact, slightly better due to less self-weight. Moreover, sisal-resin spacers have a low cost of production; they are lightweight, easy to manufacture, and have high strength and availability More research is needed to confirm the results here obtained in 3D trusses with other dimensions and geometries.

\section{Acknowledgements}

The authors want to express their gratitude to the Research Group in Civil Engineering Structures (GPEEC) of the Federal University of Cariri (UFCA) and to the Post-graduation Program in Structures and Civil Construction (PECC) of the University of Brasilia for the use of their laboratory facilities. The authors are also very thankful to CNPQ, CAPES, and FUNCAP, financial support Brazilian agencies, for providing research funding for this research.

\section{References}

[1] Cleirton A.S. Freitas, Luciano M. Bezerra, Rafael M. Araújo, Emanue C. Sousa, Geverson M. Araújo and Édipo A. Bezerra1., New experimental results of the research on Reinforced node in space truss, An International Journal Advanced Steel Construction, 13(1), 30-44, 2017.

[2] Freitas C.A.S., et al., "Polymer Composite with Sisal Fiber Used for Node Reinforce in Space-Truss with Stamped Connection", Applied Mechanics and Materials, 719-720, 202-205, 2015

[3] Souza A.C. and Gonçalves R.M., "Behavior of tubular space truss connections with stamped end bars", International Journal of Space Structures, 5, 337 - 345, 2002.

[4] Malite M., Maiola C. H., Gonçalves R.M. and Souza A.S.C., Experimental analysis of the structural performance of space trusses commonly used in Brazil, International Journal of Space Structures, 16 (4), 253-260, 2001. (ISSN: 0266-3511).

[5] Souza A.S.C., Goncalves R.M., Nardin S.D. and Calado, L., "A Strategy of Numerical Analysis of Space Truss Connections with Stamped Bar Ends," International Journal of Space Structures, 23(3), 143 - 152, 2008

[6] Subramanian, N. Space structures: Principles and Practice. Multi-Science Publishing Sussex, 213-280, 2007.

[7] Chan S.L. and Cho S.H., Second-Order P- $\Delta-\delta$ Analysis and Design of angle Trusse Allowing for Imperfections and Semi-Rigid Connections, , An International Journal Advanced Steel Construction, 1(1), 157-172, 2005.

[8] Hill D.C., Blandford G.E., Wang S.T., Post-buckling analysis of steel space trusses. J. Struct. Eng., 115(4), 900-919, 1989.

[9] Souz, A.S.C., Theoretical and experimental analysis of space trusses. DSc Thesis, School of Engineering of Sao Carlos, EESC/USP, São Paulo, 2003 (in Portuguese).

[10] Grecoa M., Gesualdoa F.A.R., Venturinib W.S. and Codab H.B., Nonlinear positional formulation for, space truss analysis, Finite Elements in Analysis and Design, 42, 1079$1086,2006$.

[11] Alegre V., Ródenas V. and Villalba, S., Collapse of the steel roof of a sports center; singular \& current pathologies, 140-156 (in Spanish): doi:http://dx.doi.org/10.21041/ra.v 2i3.33, 2014.

[12] Freitas C.A.S., Cavalcante, O.R.O., Araujo R.M. and Araújo G.M., Numerical Investigation of the Space-Truss with Reinforce of the Stamped Connection After Calibration Model in Experimental Study. In: 10th World Congress on Computational Mechanics, São Paulo. Comp. Mechanics 2012 - Proceedings, 2012-20176, 2012.

[13] Hamid Y.S., Progressive Collapse of Double Layer Space Trusses. PhD Thesis, University of Surrey, UK, 2015

[14] Bezerra L.M., Freitas, C. A. S., Matias, W. T., Nagato, Y., "Increasing load capacity of steel space trusses with end-flattened connections", Journal of Constructional Steel Research, 65 , 2197 - 2206, 2009.

[15] Freitas C.A.S., Bezerra L.M. and Silva, R.S.Y.C., "Numerical and Experimental Study of Steel Space Truss with Stamped Connection", Journal of Civil Engineering and Architecture, 5, 494-504, 2011

[16] Martin AR, Martins MA, Mattoso LHC, Silva ORRF, Chemical and structura haracterization of sisal fibers from Agave sisalana variety, Polímeros, 19:40-46, 2009.

[17] Bledzki A.K. and Gassan J., Progress Polymere Sci., 24, 221, 1999.

[18] Silva O.R.R. and Beltrão N.R.R.F., "O Agronegócio do Sisal no Brasil”, Embrapa, Brasília 1999.

[19] Martins M.A., "Fibra de Sisal: Mercerização, Acetilação e Aplicação em Compósitos de Borracha de Pneu Triturado", Tese de Doutorado, Universidade Estadual de Campinas, Brasil, 2001. 